\title{
Maternal near misses from two referral hospitals in Uganda: a prospective cohort study on incidence, determinants and prognostic factors
}

Annettee Nakimuli', Sarah Nakubulwa' ${ }^{1}$, Othman Kakaire' ${ }^{1}$, Michael O. Osinde², Scovia N. Mbalinda ${ }^{3}$, Rose C. Nabirye ${ }^{3}$, Nelson Kakande ${ }^{4}$ and Dan K. Kaye ${ }^{1 *}$

\begin{abstract}
Background: Maternal near misses occur more often than maternal deaths and could enable more comprehensive analysis of risk factors, short-term outcomes and prognostic factors of complications during pregnancy and childbirth. The study determined the incidence, determinants and prognostic factors of severe maternal outcomes (near miss or maternal death) in two referral hospitals in Uganda.

Methods: A prospective cohort study was conducted between March 1, 2013 and February 28, 2014, where cases of severe pregnancy and childbirth complications were included. The clinical conditions included abortion-related complications, obstetric haemorrhage, hypertensive disorders, obstructed labour, infection and pregnancy-specific complications such as febrile illness, anemia and premature rupture of membranes. Near miss cases were defined according to the WHO criteria. Multivariate logistic regression analysis was conducted to identify prognostic factors for severe maternal outcomes.

Results: Of 3100 women with severe obstetric complications, 130 (4.2\%) were maternal deaths and 695 (22.7 \%) were near miss cases. Severe pre-eclampsia was the commonest morbidity (incidence ratio (IR) $7.0 \%$, case-fatality rate (CFR) $2.3 \%$ ), followed by postpartum haemorrhage (IR $6.7 \%$, CFR $7.2 \%$ ). Uterine rupture (IR $5.5 \%$ ) caused the highest CFR (17.9\%), followed by eclampsia (IR $0.4 \%$, CFR $17.8 \%$ ). The three groups (maternal deaths, near misses and non-life-threatening obstetric complications) differed significantly regarding gravidity and education level. The commonest diagnostic criteria for maternal near miss were admission to the high dependency unit $(\mathrm{HDU})$ or to the intensive care unit (ICU). Thrombocytopenia, circulatory collapse, referral to a more specialized unit, intubation unrelated to anaesthesia, and cardiopulmonary resuscitation were predictive of maternal death $(p<0.05)$. Gravidity (ARR 1.4, 95 \% C1 1.0-1.2); elevated serum lactate levels (ARR 4.5, $95 \%$ Cl 2.3-8.7); intubation for conditions unrelated to general anaesthesia (ARR 2.6 (95\% Cl 1.2-5.7), cardiovascular collapse (ARR 4.9, $95 \% \mathrm{Cl}$ 2.5-9.5); transfusion of 4 or more units of blood (ARR 1.9, $95 \%$ Cl 1.1-3.1); being an emergency referral (ARR 2.6, $95 \%$ Cl 1.2-5.6); and need for cardiopulmonary resuscitation (ARR 6.1, $95 \%$ Cl 3.2-11.7), were prognostic factors.
\end{abstract}

Conclusions: The analysis of near misses is a useful tool in the investigation of severe maternal morbidity. The prognostic factors for maternal death, if instituted, might save many women with obstetric complications.

\footnotetext{
* Correspondence: dankkaye@yahoo.com

'Department of Obstetrics and Gynecology, School of Medicine, College of

Health Sciences, Makerere University, P.O. Box 7072, Kampala, Uganda

Full list of author information is available at the end of the article
} 


\section{Background}

For every maternal death, there are about 100 women with severe maternal morbidity from life-threatening obstetric complications, referred to as maternal near misses [1]. A maternal near miss was defined by the World Health Organization (WHO) as "a woman who, being close to death, survives a complication that occurred during pregnancy, delivery or up to 42 days after the end of her pregnancy" [2]. Assessment of maternal near misses offers several advantages over assessment of maternal deaths: maternal near misses are commoner than maternal deaths. In addition, review of maternal near misses yields useful information on the pathways that lead to severe morbidity and death [3]. Furthermore, near miss assessment highlights the quality of obstetric care received by those who survive [3]. Prior to the WHO definition, the estimated incidence of maternal near misses varied in different studies, ranging from less than 1 per 1000 births to 82 per 1000 live births [4-11], partly as a result of different criteria that were used in the definition of maternal near miss. The World Health Organization (WHO) [2] developed a tool which utilize a combination of clinical signs/symptoms, management practices or presence of organ-system dysfunction. Maternal mortality represents the tip of an iceberg. For each death, many other women survive serious complications during pregnancy, delivery, or puerperium that lead to varying degrees of organ-system dysfunction [2]. In many cases, the causes of maternal death are also responsible for the cases of severe morbidity [2]. The WHO tool can therefore evaluate the quality of care provided to women presenting with severe morbidity.

Conceptually, maternal near misses represent a point on the continuum where good health and death are the extreme points [12]. On this continuum, women develop obstetric complications which could be described as uncomplicated, complicated (not life- threatening), severely complicated (life-threatening) or fatal [13-15]. Such individuals may recover, become temporarily or permanently disabled, or die [12]. Three approaches were proposed for definition of maternal near miss: using clinical features (signs, symptoms or clinical entities such as eclampsia or uterine rupture) [13]; using management practices (such as admission to intensive care) [11, 12], or using criteria of organ/system dysfunction [11]. The drawback of using the clinical criteria is the definition of the threshold of severity above which morbidity qualifies to be a maternal near miss. This threshold is contextspecific as the probability of death depends on both the woman's vulnerability to succumb and access to prompt quality care [1-5]. For instance, in studies from Benin [16], Uganda [6, 17], Angola [18, 19] and Burkina Faso [20], postpartum haemorrhage qualified as a maternal near miss only when additional events such as shock, blood transfusion or hysterectomy occurred. For studies that employed the management-based criteria, hysterectomy, admission to intensive care units $[21,22]$ and prolonged hospitalization [23-29] were the commonest procedures used [21, 22]. Indicators of severity of blood loss such as hypovolemia requiring massive blood transfusion, severe anaemia with hypotension (requiring intensive resuscitation) are used to identify maternal near miss. This criterion relies heavily on availability of management facilities.

The rationale of using the organ-system dysfunctionbased criteria [11] is that women with such dysfunction are likely to die unless adequate prompt care is provided. For instance, obstetric haemorrhage constitutes a maternal near miss through vascular dysfunction (hypovolemia, shock and circulatory collapse), renal dysfunction (oliguria, acute kidney injury, renal failure), or coagulation dysfunction. The criteria rely heavily on availability of laboratory or other investigation facilities.

While assessment of maternal near miss is increasingly being recognised as potentially more useful that assessment of maternal mortality, severe maternal morbidity that constitutes a near miss is much less easy to define or quantify than maternal death. Studies that assessed maternal near miss using the WHO criteria recommended that future studies should evaluate the burden of maternal near miss using several morbidity and mortality indices [30, 31]. These indices include the maternal near miss incidence ratios, the severe maternal outcome ratio, the case-fatality ratio, the severe maternal morbidity index, and the maternal mortality ratio. To be able to reduce mortality in cases of severe maternal morbidity, there is a need to develop criteria for factors that can easily, uniformly and promptly identify prognostic factors among women with potentially life-threatening obstetric complications. There are few published studies from Africa that have used the WHO for definition of maternal near miss. Yet the WHO has recommended investigating near-misses as a benchmark practice for monitoring the quality of obstetric care and has standardized the criteria for diagnosis [2]. In addition, little is published on the burden of the maternal near miss as evidences by the morbidity severity indicators. The objective was to determine the incidence, characteristics, and prognostic factors for severe maternal outcomes (maternal near miss or maternal death) in two regional referral hospitals in central Uganda.

\section{Methods}

\section{Study setting and design}

This was a prospective cohort study of women admitted with pregnancy complications admitted between March 1, 2013 and February 28, 2014. The study was conducted at Mulago and Jinja Hospitals. Mulago is Uganda's national referral hospital and the teaching hospital for 
Makerere University. The hospital has over 1500 beds, of which over 400 are maternity beds, and conducts over 30,000 deliveries per year. Jinja is a large regional referral hospital that serves about six district hospitals in Central and Eastern Uganda. It has a capacity of over 900 beds of which over 200 are maternity beds.

\section{Data collection}

Participants were women with obstetric complications. In the selection criteria, all women with obstetric complications were enrolled into the study, irrespective of the severity of complications. Depending on the severity, the WHO criteria [2] were used to classify survivors of severe obstetric complications into maternal near miss morbidity (according to the criteria recommended by the tool), or those with non-life threatening obstetric complications. Women who consented to participate were recruited in the study. Using an interviewer-administered questionnaire, participant examination, investigations and through review of medical records, data was collected on sociodemographic characteristics, obstetric history, current pregnancy complications and pregnancy outcomes up to the time participants were discharged from hospital or died. Data for women with no or minor obstetric complications was excluded from the analysis.

\section{Sample size estimation}

Assuming a power of $80 \%$ at the $95 \%$ significance level and a maximum accepted error of $5 \%$, and an assumed incidence ratio of obstetric complications of $15 \%$ of all women who deliver, and assuming that $50 \%$ of women with severe obstetric complications would end up as maternal near misses, our sample size was estimated to be 2600 women with obstetric complications of whom about 385 would be women with severe obstetric morbidity (near misses).

\section{Data analysis}

We computed descriptive characteristics of maternal near miss, whereby categorical variables were presented as frequencies and percentages while numerical variables are presented as means or medians (with standard deviations or inter-quartile ranges respectively). In addition, we computed the following indicators: i) The maternal near miss incidence ratios derived as the ratio of near miss per 1000 live births respectively; ii.) The severe maternal outcome ratio as ratio of maternal death plus near misses per 1000 live births; iii) The case-fatality rate for maternal complications determined as the proportion of deaths out of the total number of patients presenting with specific complications, expressed as a percentage; iv) The severe maternal mortality index, derived as maternal deaths divided by (total deaths plus maternal near misses) expressed as a percentage; v) The maternal mortality ratio expressed as all maternal deaths per 100,000 live births as well as the perinatal mortality ratio expressed as all perinatal deaths per 1000 live births.

Furthermore, we analysed risk factors for severe maternal outcomes (maternal near miss or maternal death). Categorical variables were compared with $X^{2}$ square or Fisher's exact test and continuous variables with a twotailed Student $t$ test. We further analysed the prognostic factors of maternal near miss using log binomial regression analysis, where characteristics of near misses and maternal deaths were compared and adjusted relative risks computed. Variables included in the models were those with a $p$-value less than or equal to 0.2 or important from a clinical standpoint. After assessing the effects of confounding, interaction and collinearity, the final model contained mainly the laboratory-based and managementbased criteria (for diagnosis of a maternal near miss).

\section{Ethical considerations}

This research was part of a post-doctoral research project of the first author (DKK) entitled: "Evaluation and surveillance of the impact of maternal and neonatal near-miss morbidity on the health of mothers and infants in Jinja and Mulago hospitals". Ethical approval to conduct the study was obtained from the Ethics and research committees of Mulago hospital (REC 310-2012), the School of Medicine, Makerere University College of Health Sciences (REC 2012-172) and from Uganda National Council for Science and Technology. Permission to conduct the study was obtained from the department of Obstetrics and Gynaecology, Makerere University, and from Mulago National Referral Hospital and Jinja Hospital.

Participants gave written informed consent to be enrolled in the study and for their data to be included in the study. Participants included minors (aged 14-17years), as Uganda national guidelines for human subject research [32] allow research on mature and emancipated minors in certain situations such as in pregnancy, with prior approval of an institutional review board. For those with very severe morbidity, consent was obtained retrospectively when they recovered, or consent was obtained from the next of kin to involve the patients' in the study and to include the patients' data in our dataset. Participants and their next of kin received assurances that participation was voluntary, and that participants were free to stop participation at any time without their decision affecting the care they were entitled to. All those with complications, and their newborns, were provided free medical care or, where necessary, were offered additional counselling or referred to get other support services not available at the two health facilities. Permission was obtained from the management of the two referral hospital (and from the study participants) to review the participants' records. 


\section{Results}

Of the 3100 women with severe obstetric complications, there were 130 maternal deaths (4.2\%), 695 maternal near miss cases $(22.7 \%)$ and 2275 (73.4\%) women with nonlife threatening obstetric complications (NLTC). In the same period, there were 25,840 live births. Table 1 shows the indicators for maternal and perinatal morbidity and mortality. The main cause was severe pre-eclampsia, with an incidence of 216 cases (7.0\%), but with a case fatality rate of only $2.3 \%$. Postpartum haemorrhage was the second main cause of morbidity, contributing to 208 of the 3100 cases $(6.7 \%)$ with a case-fatality rate of $7.2 \%$. However, uterine rupture caused the highest case-fatality of 27 out of 151 (17.9\%), followed by eclampsia (13 out of 171 or $17.8 \%)$.

Table 2 shows the socio-demographic characteristics and medical history of the participants, stratified by severity of complications. The three groups differed significantly regarding their gravidity, education level and timing of the obstetric complications. Table 3 shows the obstetric complications displayed according to the maternal outcomes. In relation to the childbirth event, the most likely time for a mother to develop severe maternal outcomes was if they occurred in the intrapartum period and continued in the postpartum period (RR 2.5, $95 \%$ CI 1.5-4.2, $p$-value $<0.001)$; or if complications

Table 1 Maternal perinatal and neonatal mortality indicators

\begin{tabular}{ll}
\hline Indicators & Ratio \\
\hline Maternal near miss ratio & 8.42 per 1000 live births. \\
Severe maternal outcome ratio & 9.99 per 1000 live births \\
Maternal mortality ratio (MMR) & 503 per 100,000 live births. \\
Severe maternal mortality index & $15.8 \%$ \\
Case-specific mortality rates & \\
Puerperal sepsis (9 out of 142) & $6.3 \%$ \\
Severe obstructed labor (19 out of 564) & $3.4 \%$ \\
Abortion-related deaths & \\
Abortion haemorrhage (5 out of 41) & $12.2 \%$ \\
Postabortion sepsis (5 of 114) & $4.4 \%$ \\
$\quad$ Overall (10 out of 155) & $6.5 \%$ \\
Obstetric hemorrhage & \\
Antepartum haemorrhage & \\
(5 out of 136) & $5.1 \%$ \\
Postpartum haemorrhage & \\
(15 out of 208) & $7.2 \%$ \\
Ruptured uterus (27 out of 151) & $17.9 \%$ \\
Hypertensive disorders & \\
Severe preeclampsia (5 out of 216) & $2.3 \%$ \\
Eclampsia (13 out of 171) & $17.8 \%$ \\
HELLP Syndrome (2 out of 7) & $28.6 \%$ \\
\hline Overall (20 out of 394) & $5.1 \%$ \\
\hline
\end{tabular}

occurred in the postpartum period ( $\mathrm{RR} 1.8,95 \% \mathrm{CI}$ $1.0-3.0 ; p$-value $=0.044)$.

Table 4 shows the diagnostic criteria used for the definition of severe maternal outcomes (maternal near miss cases and maternal deaths) in the 192 women with obstetric complications. The commonest clinical criteria used to diagnose severe maternal outcomes were shock (as indicated by very low blood pressure or circulatory collapse and respiratory rate of more than 40 or less than 6 per minute). The commonest management-based criteria were admission to the HDU or ICU, and prolonged hospitalization longer than 7 days. The commonest laboratory-based criterion was thrombocytopenia (platelet count less than 100,000 per $100 \mathrm{ml}$ ). Shock, prolonged comatose state (for up to $12 \mathrm{~h}$ ) and circulatory collapse pulse were predictive of maternal death $(p<0.05)$. Referral to a more specialized unit, admission to the HDU or ICU, intubation unrelated to anaesthesia, and cardiopulmonary resuscitation were management-based criteria that were predictive of a maternal death $(p<0.05)$. Laboratory-based diagnostic criteria were not predictive of maternal death $(p>0.05)$.

Table 5 shows the prognostic factors for maternal near miss. Gravidity (ARR 1.1, $95 \%$ C1 1.0-1.2), elevated serum lactate levels (ARR 4.5, 95 \% CI 2.3-8.7), intubation for conditions unrelated to general anaesthesia (ARR 2.6 (95 \% CI 1.2-5.7), cardiovascular collapse(ARR 4.9, $95 \%$ CI 2.5-9.5), transfusion of 4 or more units of blood (ARR 1.9, $95 \%$ CI 1.1-3.1), being a referral (ARR 2.6, $95 \%$ CI 1.2-5.6), and cardiopulmonary resuscitation (ARR 6.1, 95 \% CI 3.2-11.7) were prognostic factors.

\section{Discussion}

The term near-miss describes a serious adverse event whereby death did not occur either due to luck or prompt adequate management [33]. This concept was defined by the World Health Organization (WHO) as "a woman who, being close to death, survives a complication that occurred during pregnancy, delivery or up to 42 days after the end of her pregnancy" [2]. The WHO criteria employ presence of organ dysfunction or a combination of clinical features, laboratory findings and management practices).

Our results show that the WHO maternal near miss tool [2] is useful in investigating both maternal morbidity and the quality of care provided to women with severe obstetric complications. This study is innovative in that it was conducted in two referral centres (the national referral and one regional referral hospital), the sample size is quite large, and the study design was prospective. In addition, the study used the WHO criteria for definition of maternal near-miss, and indicators of organ-system dysfunction were assessed as prognostic factors. In this study, the WHO tool enabled identification of nearly 7 times more cases of severe morbidity compared to what assessment of maternal mortality could have yielded. 
Table 2 Socio-demographic characteristics and medical history of the participants with obstetric complications displayed according to maternal outcomes

\begin{tabular}{|c|c|c|c|c|c|}
\hline \multirow[t]{2}{*}{ Characteristics } & $\begin{array}{l}\text { Number } \\
\text { (percentage) }\end{array}$ & $\begin{array}{l}\text { Number } \\
\text { (percentage) }\end{array}$ & $\begin{array}{l}\text { Number } \\
\text { (percentage) }\end{array}$ & $\begin{array}{l}\text { Number } \\
\text { (percentage) }\end{array}$ & \multirow{2}{*}{$\begin{array}{l}p \text {-value } \\
\text { (testing } \\
\text { difference } \\
\text { in groups) }\end{array}$} \\
\hline & All patients & Maternal deaths & Maternal near miss & NLTC & \\
\hline \multicolumn{5}{|l|}{ Age category } & \multirow[t]{4}{*}{0.447} \\
\hline 18 years or less & $256(8.3)$ & $11(8.5)$ & $57(8.2)$ & $188(8.3)$ & \\
\hline 19-24 years & 1207 (38.9) & $48(36.9)$ & $251(36.1)$ & 908 (39.9) & \\
\hline$>=24$ years & $1637(52.8)$ & $71(54.6)$ & $387(55.7)$ & $1179(51.7)$ & \\
\hline \multicolumn{5}{|l|}{ Gravidity } & \multirow[t]{4}{*}{$<0.001$} \\
\hline 1 & $999(32.2)$ & $29(22.3)$ & $184(26.5)$ & 786 (34.6) & \\
\hline $2-4$ & 1519 (49.0) & $62(47.7)$ & $357(51.4)$ & $1100(48.4)$ & \\
\hline 5 and more & $582(18.8)$ & $39(30.0)$ & $154(22.2)$ & $389(17.1)$ & \\
\hline \multicolumn{5}{|l|}{ Marital status } & \multirow[t]{4}{*}{0.249} \\
\hline Single & $519(16.7)$ & $23(17.7)$ & $134(19.3)$ & $362(15.9)$ & \\
\hline Married & $2571(83.0)$ & $107(82.3)$ & $560(80.7)$ & $1904(83.9)$ & \\
\hline Separated & $10(0.3)$ & $0(0.0)$ & $0(0.0)$ & $10(0.4)$ & \\
\hline \multicolumn{5}{|l|}{ Employment status } & \multirow[t]{4}{*}{0.053} \\
\hline Formal & $304(9.8)$ & $9(6.3)$ & $68(9.8)$ & $228(10.0)$ & \\
\hline Informal & $994(32.1)$ & $39(30.2)$ & $251(36.2)$ & $704(31.0)$ & \\
\hline Unemployed & $1797(58.1)$ & $82(63.6)$ & $376(56.0)$ & $1343(59.0)$ & \\
\hline \multicolumn{5}{|l|}{$\Omega$ Education level } & \multirow[t]{4}{*}{$<0.001$} \\
\hline None or primary level & $1275(41.4)$ & $72(56.3)$ & $309(44.7)$ & $894(39.5)$ & \\
\hline Secondary level & $1472(47.8)$ & $49(38.2)$ & $309(44.7)$ & $1114(49.3)$ & \\
\hline Post-secondary (tertiary) & $333(10.8)$ & $7(5.5)$ & 75 (10.6) & $253(11.2)$ & \\
\hline \multicolumn{5}{|l|}{ Referral status } & \multirow[t]{3}{*}{0.121} \\
\hline Referred & $2064(66.7)$ & $97(74.6)$ & $453(65.3)$ & $1514(66.6)$ & \\
\hline Not Referred (self-referrals) & 1036 (33.3) & $33(25.4)$ & $242(34.7)$ & $760(33.4)$ & \\
\hline \multicolumn{6}{|l|}{ Timing of complications } \\
\hline Occurred before admission & $1189(53.8)$ & $48(36.9)$ & $324(46.6)$ & $817(35.9)$ & \multirow[t]{3}{*}{$<0.001$} \\
\hline $\begin{array}{l}\text { Occurred before arrival and new } \\
\text { complications developed }\end{array}$ & $565(25.6)$ & $46(27.6)$ & $239(34.4)$ & $290(12.8)$ & \\
\hline Complications occurred during hospitalized & $458(20.6)$ & $48(35.4)$ & $132(18.9)$ & $1168(51.3)$ & \\
\hline \multicolumn{6}{|l|}{ Admission to the HDU } \\
\hline Yes & $541(17.5)$ & $71(54.6)$ & $464(66.8)$ & $6(0.3)$ & \multirow[t]{2}{*}{0.750} \\
\hline No & 2559 (82.5) & $59(45.4)$ & 231 (33.2) & $2269(99.7)$ & \\
\hline
\end{tabular}

Key: NLTC non-life-threatening obstetric complications

Severe pre-eclampsia was the commonest morbidity, followed by postpartum haemorrhage. However, uterine rupture caused the highest case-fatality followed by eclampsia. The commonest diagnostic criteria for maternal near miss were admission to the high dependency unit (HDU) or to the intensive care unit (ICU). Gravidity, elevated serum lactate levels, intubation for conditions unrelated to general anaesthesia, cardiovascular collapse, transfusion of 4 or more units of blood, being a referral, and need for cardiopulmonary resuscitation were prognostic factors.
Our finding show no differences on socio-demographic characteristics (except for education level and gravidity) and medical history between the three groups (NLTC, near miss cases and maternal deaths). Therefore, the different clinical causes of morbidity differ only according to severity of the complications. In addition, the outcomes may not depend so much on the socio-demographic or medical history as on the quality of care individuals receive. The outcome of critically ill patients, such as patients with severe obstetric complications, is dependent on clinical and individual factors, previous health status, 
Table 3 Obstetric complications in women displayed according to the maternal outcomes

\begin{tabular}{|c|c|c|c|c|c|}
\hline \multirow[t]{3}{*}{ Characteristics } & Number (percentage) & Number (percentage) & Number (percentage) & Number (percentage) & \multirow[t]{3}{*}{$p$-value } \\
\hline & All patients & Maternal deaths & Maternal near miss & NLTC & \\
\hline & $N=3100$ & $N=130$ & $N=695$ & $N=2275$ & \\
\hline SObstetric Haemorrhage & & & & & $<0.001$ \\
\hline Antepartum & $136(4.4)$ & $7(5.4)$ & $82(11.8)$ & $47(2.0)$ & \\
\hline Postpartum & $230(7.4)$ & $35(26.9)$ & $102(14.7)$ & $93(4.0)$ & \\
\hline Ruptured uterus & $154(5.0)$ & $27(20.8)$ & $115(16.5)$ & $12(0.5)$ & \\
\hline$\Omega$ Abortion-related & & & & & 0.007 \\
\hline Haemorrhage & $41(1.3)$ & $5(3.8)$ & $23(3.3)$ & $13(0.6)$ & \\
\hline Postabortion sepsis & $8(0.3)$ & $0(0.0)$ & $6(0.9)$ & $2(0.1)$ & \\
\hline Septic abortion & $20(0.6)$ & $0(0.0)$ & $10(1.4)$ & $10(0.4)$ & \\
\hline Hypertensive disorders & & & & & $<0.001$ \\
\hline Severe Preeclampsia & $218(7.0)$ & $5(3.8)$ & 79 (11.4) & $134(6.0)$ & \\
\hline Eclampsia & $172(5.5)$ & $13(10)$ & $132(19.0)$ & $27(1.2)$ & \\
\hline Chronic Hypertension & $4(0.1)$ & $0(0.0)$ & $4(0.6)$ & $0(0.0)$ & \\
\hline HELLP Syndrome & $9(0.3)$ & $2(1.5)$ & $7(1.0)$ & $0(0.0)$ & \\
\hline Puerperal sepsis & $114(3.7)$ & $14(10.8)$ & $82(11.8)$ & $18(0.8)$ & $<0.001$ \\
\hline Obstructed labor & $564(18.2)$ & 19 (14.6) & $42(6.0)$ & $503(22.1)$ & $<0.001$ \\
\hline Timing of the complications & & & & & $<0.001$ \\
\hline$\&^{a}$ Antepartum & $1431(48.1)$ & $39(30.0)$ & $263(37.8)$ & $1129(49.6)$ & \\
\hline Postpartum & $156(5.2)$ & $5(3.9)$ & $59(8.5)$ & $92(4.0)$ & \\
\hline Intrapartum & $571(19.2)$ & $20(15.6)$ & $133(19.1)$ & $418(18.4)$ & \\
\hline Antepartum and intrapartum & $449(15.1)$ & $34(26.1)$ & $91(13.1)$ & $324(14.2)$ & \\
\hline Intrapartum and postpartum & $325(10.9)$ & $27(20.0)$ & $100(14.4)$ & $199(8.8)$ & \\
\hline Occurred in all three periods & $45(1.5)$ & $6(4.6)$ & $49(7.0)$ & $113(5.0)$ & \\
\hline$\infty$ Mode of delivery & & & & & $<0.001$ \\
\hline Vaginal delivery & $234(15.5)$ & $23(28.4)$ & $115(21.2)$ & $96(10.8)$ & \\
\hline$\beta$ Caesarean section or laparotomy & $1266(83.8)$ & $56(69.1)$ & $424(78.1)$ & $786(88.7)$ & \\
\hline Assisted delivery & $10(0.7)$ & $2(2.5)$ & $4(0.7)$ & $4(0.5)$ & \\
\hline
\end{tabular}

$\Omega$ Multiple responses, so percentage does not add up to $100 \%$; ${ }^{a}$ Antepartum complications include sickle cell anemia, severe asthmatic attack and severe malaria in pregnancy; \& All antenatal and abortion complications included in this group; $\infty$ Mode of delivery for 1510 women where delivery occurred; $\beta$ Laparotomy for ruptured uterus

physiologic reserve, disease severity and adequacy of care provided [34, 35]. The severity depends on the inherent risk of disease progression and the quality of care received in terms of timeliness, adequacy and comprehensiveness. Since near miss cases share characteristics with maternal deaths, they may be used to provide information about hurdles that needed to be overcome after onset of or worsening of complications. In that way, near misses provide invaluable information on obstetrical care.

The WHO maternal near miss tool may be used as a scoring tool for severe obstetric morbidity. The complications that are unique to pregnancy or childbirth and the changed physiologic parameters (as a result of pregnancy changes) make pregnancy, childbirth and the puerperium unique situations where routinely used scoring systems for disease severity may be inappropriate or inadequate
$[35,36]$. Many of the available scoring systems of disease are not applicable to disease severity in obstetric complications [34, 35]. Indeed the traditional risk stratification models used in critically ill non-obstetric patients usually overestimate mortality among pregnant women, which makes analysis of morbidity data especially prognostic factors and their interpretation difficult $[36,37]$.

The WHO maternal near miss tool is an innovative concept that could be used to identify prognostic indicators for patients with severe maternal morbidity [37, 38]. Early recognition and prompt management of severe life-threatening maternal morbidity through improved access, availability and affordability of critical life-saving skills and therapeutics is key to reduction of maternal morbidity and mortality. This calls for tools to assess prognostic factors in maternal near miss cases. 
Table 4 Diagnostic criteria used for the definition of severe maternal outcomes (maternal near miss cases and maternal deaths) in the 3100 women with obstetric complications (including abortion-related complications)

\begin{tabular}{|c|c|c|c|c|}
\hline \multirow[t]{3}{*}{ Characteristics } & All women & Maternal deaths & Maternal near miss & \multirow[t]{3}{*}{$p$-value } \\
\hline & $\begin{array}{l}\text { Number } \\
n=3100\end{array}$ & $\begin{array}{l}\text { Number } \\
(n=130)\end{array}$ & $\begin{array}{l}\text { Number } \\
(n=695)\end{array}$ & \\
\hline & N (\%) & N (\%) & N (\%) & \\
\hline \multicolumn{5}{|l|}{$\Omega$ Clinical criteria } \\
\hline Cyanosis & $442(14.3)$ & $69(53.1)$ & $370(53.2)$ & 0.973 \\
\hline Breathing rate more than 40 or less than 6 per minute & $521(16.8)$ & $77(59.2)$ & $440(63.3)$ & 0.378 \\
\hline Oliguria poorly or unresponsive to fluids or diuretics & $450(14.8)$ & $62(47.7)$ & $386(55.7)$ & 0.093 \\
\hline Loss of consciousness for up to $12 \mathrm{~h}$ & $268(8.7)$ & $51(39.2)$ & $213(30.6)$ & 0.050 \\
\hline Unconscious (coma) with without recordable pulse & $164(5.3)$ & $43(33.1)$ & $121(17.4)$ & $<0.001$ \\
\hline Gasping due to low $\mathrm{PaO} 2$ or pulmonary edema & $140(4.5)$ & $23(17.7)$ & $117(17.8)$ & 0.811 \\
\hline 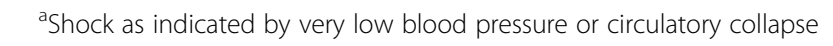 & $606(19.6)$ & $72(55.4)$ & $533(76.4)$ & $<0.001$ \\
\hline $\begin{array}{l}{ }^{a} \text { Coagulation disorders evidenced by low platelets, elevated bleeding } \\
\text { or clotting time, or bleeding tendency }\end{array}$ & $362(11.7)$ & $50(38.5)$ & $310(44.6)$ & 0.195 \\
\hline Cerebrovascular accident & $17(0.6)$ & $5(3.8)$ & $12(1.7)$ & 0.118 \\
\hline Paralysis & $13(0.4)$ & $1(0.8)$ & $12(1.6)$ & 0.477 \\
\hline \multicolumn{5}{|l|}{$\Omega$ Laboratory-based criteria } \\
\hline aBilirubin more than $100 \mathrm{~mol} / \mathrm{l}$ or more than $6.0 \mathrm{mg} / \mathrm{dL}$ & $274(8.8)$ & $44(33.8)$ & $226(32.7)$ & 0.792 \\
\hline${ }^{a}$ Thrombocytopenia (less than 100,000) & $436(14.1)$ & $60(46.2)$ & $373(53.7)$ & 0.115 \\
\hline Creatinine more than $300 \mathrm{~mol} / / \mathrm{l}$ or more than $3.5 \mathrm{mg} / \mathrm{dL}$ & $295(9.5)$ & $47(36.2)$ & $245(35.3)$ & 0.844 \\
\hline Elevated lactate & $272(8.8)$ & $40(30.8)$ & $229(33.0)$ & 0.626 \\
\hline Low pH less than 7.1 & $255(8.3)$ & $31(24.0)$ & $221(31.8)$ & 0.071 \\
\hline \multicolumn{5}{|l|}{$\Omega$ Management-based criteria } \\
\hline Oxygen saturation less than $90 \%$ for more than 60 min & $499(16.1)$ & $71(54.6)$ & $426(61.3)$ & 0.153 \\
\hline Use of vasoactive drug such as ephedrine & $204(6.6)$ & $36(27.7)$ & $168(24.2)$ & 0.393 \\
\hline Dialysis for acute kidney failure & $62(2.0)$ & $13(10.0)$ & $49(7.2)$ & 0.242 \\
\hline Peripartum hysterectomy cardiopulmonary & $169(5.5)$ & $12(9.2)$ & $81(11.7)$ & 0.423 \\
\hline resuscitation & $110(3.6)$ & $96(73.8)$ & $619(88.9)$ & $<0.001$ \\
\hline 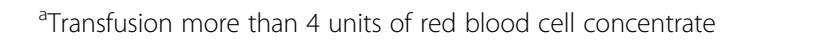 & $270(8.7)$ & $40(30.8)$ & $225(32.4)$ & 0.719 \\
\hline antubation unrelated to anesthesia & $124(4.1)$ & $32(24.6)$ & $79(11.4)$ & $<0.001$ \\
\hline Admission to the $\mathrm{HDU}$ or ICU & $541(17.5)$ & $71(54.6)$ & $464(66.8)$ & 0.008 \\
\hline${ }^{a}$ Hospitalization longer than 7 days & $537(17.5)$ & $34(26.1)$ & $496(71.4)$ & $<0.001$ \\
\hline${ }^{a}$ Return to operation theatre & $67(2.2)$ & $14(10.8)$ & $52(7.4)$ & 0.205 \\
\hline Referral to a more specialized unit & $5(1.5)$ & $16(14.0)$ & $27(3.9)$ & $<0.001$ \\
\hline Major operative non-obstetric surgery & $9(0.3)$ & $2(1.5)$ & $7(1.0)$ & 0.592 \\
\hline
\end{tabular}

$\Omega$ More than one criterion was manifest in some patients; $H D U$ is the high dependency unit, $I C U$ is Intensive care Unit; ${ }^{a}$ Some patients were among those with NLTC

The Sequential Organ Failure Assessment (SOFA) score is a validated score used to quantify organ dysfunction and predict prognosis for severely ill persons admitted to the ICU $[39,40]$. The SOFA score is one of the scoring systems used to track a patient's status during the stay in an ICU where it is used to determine the extent of a person's organ function or rate of failure. The score is based on six different scores, one each for the respiratory, cardiovascular, hepatic, coagulation, renal and neurological systems. Both the mean and highest SOFA scores are predictive of mortality outcomes: an increase in SOFA score during the first 24 to $48 \mathrm{~h}$ in the ICU predicts a mortality rate in $50-95 \%$ of cases $[39,40]$. In a study of obstetric patients admitted to ICU, which compared scores on the WHO tool and the total maximum Sequential Organ Failure (SOFA) score as the gold standard, the WHO near miss criteria had a sensitivity and specificity of $99.2 \%$ and $86.0 \%$ respectively for identification of organ failure in at least one organ system [39]. In addition, the WHO tool had a sensitivity of $100 \%$ and specificity 
Table 5 Prognostic factors for severe maternal outcomes in women with severe maternal outcomes (maternal deaths plus near misses)

\begin{tabular}{|c|c|c|c|c|c|c|}
\hline \multirow[t]{2}{*}{ Characteristic } & \multirow{2}{*}{$\begin{array}{l}\text { Maternal deaths } \\
\text { N (\%) }\end{array}$} & $\begin{array}{l}\text { Maternal near } \\
\text { miss morbidity }\end{array}$ & \multirow[t]{2}{*}{$\begin{array}{l}\text { Crude risk ratios } \\
\text { and } 95 \% \mathrm{Cl}\end{array}$} & \multirow[t]{2}{*}{$p$-values } & \multirow{2}{*}{$\begin{array}{l}\text { Adjusted } \\
\text { risk ratios } \\
\text { and } 95 \% \mathrm{Cl}\end{array}$} & \multirow[t]{2}{*}{$p$-values } \\
\hline & & N (\%) & & & & \\
\hline \multicolumn{7}{|l|}{${ }^{a}$ Referral } \\
\hline Yes & $16(12.3)$ & $27(28.4)$ & 3.5 & & 2.6 & \\
\hline No & $114(87.7)$ & $668(71.6)$ & $(1.8-6.6)$ & $<0.001$ & $(1.2-5.6)$ & 0.013 \\
\hline Admission to the ICU or HDU & & & & & & 0.018 \\
\hline Yes & $71(54.6)$ & $464(66.8)$ & 1.3 & 0.008 & 1.9 & \\
\hline No & $59(45.4)$ & $231(33.2)$ & $(1.1-2.4)$ & & $(1.1-3.1)$ & \\
\hline$C P R$ & & & & & & $<0.001$ \\
\hline Yes & $34(26.2)$ & $76(10.9)$ & 2.9 & $<0.001$ & 6.1 & \\
\hline No & $96(73.8)$ & $619(89.1)$ & $(1.8-4.6)$ & & $(3.2-11.7)$ & \\
\hline Transfusion more than 4 units & & & & & & 0.013 \\
\hline Yes & $40(30.8)$ & $225(32.3)$ & 1.9 & & 1.9 & \\
\hline No & $90(69.2)$ & $470(67.7)$ & $(1.3-2.7)$ & 0.002 & $(1.1-3.1)$ & \\
\hline Cardiovascular collapse & & & 2.9 & & & $<0.001$ \\
\hline Yes & 43(33.1) & $121(17.4)$ & $(1.8-4.7)$ & $<0.001$ & 4.9 & \\
\hline No & $87(66.9)$ & $574(82.6)$ & & & $(2.5-9.5)$ & \\
\hline Hypotension & & & & & & $<0.001$ \\
\hline Yes & $72(55.4)$ & $531(76.0)$ & 2.6 & $<0.001$ & 2.6 & \\
\hline No & $58(44.6)$ & $164(24.0)$ & $(1.8-3.8)$ & & $(1.6-4.4)$ & \\
\hline Intubation & & & & & & $<0.001$ \\
\hline Yes & $31(31.3)$ & $95(13.7)$ & 5.0 & & 2.6 & \\
\hline No & $99(68.7)$ & $600(86.3)$ & $(3.4-7.6)$ & $<0.001$ & $(1.2-5.7)$ & \\
\hline Elevated serum lactate & & & & & & $<0.001$ \\
\hline Yes & $40(30.8)$ & $229(32.9)$ & 1.5 & 0.078 & 4.5 & \\
\hline No & $90(69.2)$ & $466(67.1)$ & $(0.9-2.4)$ & & $(2.3-8.7)$ & \\
\hline$\beta$ Gravidity & & & & & & 0.042 \\
\hline Gravid 1-4 & $100(76.9)$ & $541(77.8)$ & 1.2 & 0.046 & 1.1 & \\
\hline Gravida 5 or more & $30(23.1)$ & $154(22.2)$ & $(1.1-1.4)$ & & $(1.0-1.2)$ & \\
\hline Thrombocytopenia & & & & & & 0.337 \\
\hline Yes & $60(46.1)$ & $373(53.7)$ & 1.4 & 0.116 & 1.4 & \\
\hline No & $70(53.9)$ & $322(46.3)$ & $(0.9-1.9)$ & & $(0.7-3.20$ & \\
\hline
\end{tabular}

$H D U$ high dependency unit, ICU intensive care unit, $R R$ relative risk, $C l$ confidence intervals, $C P R$ cardiopulmonary resuscitation; ${ }^{a}$ Referral to another unit outside the obstetric unit; $\beta$ Comparing gravida 5 or more versus gravida 4 and less; $\infty 68$ women died within the first 7 days after admission, and therefore not included in the analysis

$70.4 \%$ for prediction of maternal deaths [39]. The total maximum SOFA score had a good performance (area under the curve of 0.897 ) for prediction of cases of maternal near miss according to the WHO criteria [39]. In another study assessing the utility of the SOFA score in obstetric patients, the total maximum SOFA score was significantly higher in women with severe maternal morbidity (SMM) when compared to that in women without SMM $(p<0.001)$ [40]. In addition, the total maximum SOFA score was predictive of survival by being able to discriminate pregnant women with SMM who did not survive (AUROC 0.77, 95 \% CI: 0.46, 1.00) [40]. The WHO tool is therefore useful in identification of organ-system dysfunction and multiple organ failure, which is the final cause of death in patients with severe obstetric complications.

The analysis of maternal near misses is a useful innovation in the investigation of severe maternal morbidity [41], though it may require modification in certain contexts. For instance, in a study conducted in Tanzania using a modification of the tool [42], 216 maternal near misses and 32 maternal deaths were identified over a two year-period. From a hospital based study that used a modification of the WHO tool [43], the maternal mortality ratio was 350 maternal deaths per 100,000 live 
births, the maternal near miss incidence ratio was 23.6 per 1000 live births, and the overall case fatality rate was $12.9 \%$. The use of the WHO tool underscores the practical challenges in determining organ-system dysfunction in obstetric patients. The evidence that the WHO tool scores fairly well in recognising organ dysfunction and failure when compared with standard tools such as the SOFA for assessing organ failure [44, 45], increases its utility in obstetric patients.

\section{Conclusion}

In conclusion, the WHO tool for analysis of maternal near miss, which uses defined criteria, can identify more preventable causes of maternal death than the traditional clinical criteria alone. Prospective monitoring of maternal morbidity may be useful in identifying determinants and prognostic factors of severe maternal morbidity.

\section{Abbreviations \\ ARR: adjusted risk ratio; Cl: confidence intervals; CPR: cardiopulmonary resuscitation; HDU: high dependency obstetric unit; HELLP \\ syndrome: syndrome of hemolysis, elevated liver enzymes and low platelets; ICU: intensive care unit; NLTC: non-life threatening obstetric complication; RR: risk ratio; SIDA: Swedish International Development Agency; SMM: severe maternal morbidity; SOFA: sequential organ failure assessment; WHO: World Health Organization.}

\section{Competing interests}

The authors declare that they have no competing interests.

\section{Authors' contributions}

DKK conceptualized the study the post-doctoral research project of which this study was a part. OK, MOO, SNM, RCN, AN and SN advised on the design and data collection. DKK collected the data, led the analysis, and wrote the text of the paper. All co-authors advised on the data analysis, reviewed and edited several versions of the drafts and approved the final manuscript.

\section{Acknowledgements}

This study was part of a post-doctoral research project for DKK funded by the Swedish International Development Agency (SIDA) through the Makerere University-Karolinska Institutet postdoctoral-research grants. The findings and conclusions of this article are those of the authors and do not necessarily represent the views of the funders. We are grateful to all women and newborns who participated in this study.

\section{Author details \\ 'Department of Obstetrics and Gynecology, School of Medicine, College of Health Sciences, Makerere University, P.O. Box 7072, Kampala, Uganda. ${ }^{2}$ Department of Obstetrics and Gynecology, Jinja Regional Hospital, Jinja, Uganda. ${ }^{3}$ Department of Nursing, School of Health Sciences, College of Health Sciences, Makerere University, P.O. Box 7072, Kampala, Uganda. ${ }^{4}$ Clinical, Operations and Health Services Research Program, Joint Clinical Research Centre, P. O. Box 10005, Kampala, Uganda.}

Received: 24 December 2014 Accepted: 21 January 2016

Published online: 28 January 2016

\section{References}

1. Report on the World Health Organization working group on the classification of maternal deaths and severe maternal morbidities. Geneva: World Health Organization; 2009.

2. Say L, Souza JP, Pattinson RC. Maternal near miss - towards a standard tool for monitoring quality of maternal health care. Best Pract Res Clin Obstet Gynecol. 2009;23:287-96.

3. Ronsmans C, Filippi V. Beyond the numbers Reviewing maternal deaths and complications to make pregnancy safer. Reviewing severe maternal morbidity and learning from women who survive life threatening complications. Geneva: World Health Organization; 2004

4. Adisasmita A, Deviany PE, Nandiaty F, Stanton C, Ronsmans C. Obstetric near-miss and deaths in public and private hospitals in Indonesia. BMC Pregnancy Childbirth. 2008;8:10.

5. Souza JP, Cecatti JG, Parpinelli MA, de Sousa MH, Serruya SJ. Systematic review of near miss maternal morbidity. Cad Saude Publica. 2006;22:255-64

6. Minkauskien M, Nadisauskiene R, Padaiga Z, Makari S. Systematic review on the incidence and prevalence of severe maternal morbidity. Medicina. 2004;40:299-309.

7. Okong P, Byamugisha J, Mirembe F, Byaruhanga R, Bergstrom S. Audit of severe maternal morbidity in Uganda-implications for quality of care. Acta Obstet Gynecol Scand. 2006;85:797-804

8. Souza JP, Cecatti JG, Parpinelli MA, Serruya SJ, Amaral E. Appropriate criteria for identification of near-miss maternal morbidity in tertiary care facilities: a cross sectional study. BMC Pregnancy Childbirth. 2007;7:20

9. Gandhi MN, Welz T, Ronsmans C. An audit of life-threatening maternal morbidity in rural South Africa using 'near-miss' criteria adapted for primary level hospitals. Int J Gynecol Obstet. 2004:87:180-7.

10. Waterstone M, Bewley S, Wolfe C. Incidence and predictors of severe obstetric morbidity: case-control study. BMJ. 2001;322(7294):1089-94.

11. Mantel GD, Buchmann E, Rees H, Pattinson RC. Severe acute maternal morbidity: a pilot study of a definition for a near-miss. Br J Obstet Gynecol. 1998;105(9):985-90.

12. Geller SE, Rosenberg D, Cox SM, Brown ML, Simonson L, Driscoll CA, et al. The continuum of maternal morbidity and mortality: factors associated with severity. Am J Obstet Gynecol. 2004;191(3):939-44.

13. Stones W, Lim W, Al-Azzawi F, Kelly M. An investigation of maternal morbidity with identification of life threatening 'near miss' episodes. Health Trends. 1991;23(1):13-5.

14. Glazener CM, Abdalla M, Stroud P, Naji S, Templeton A, Russell IT. Postnatal maternal morbidity: extent, causes, prevention and treatment. Br J Obstet Gynaecol. 1995;102:282-7.

15. Waterstone M, Wolfe C, Hooper R, Bewley S. Postnatal morbidity after childbirth and severe obstetric morbidity. BJOG. 2003:110:128-33.

16. Filippi V, Alihonou E, Mukantaganda S, Graham WJ, Ronsmans C. Near misses: maternal morbidity and mortality. Lancet. 1998:351(9096):145-6.

17. Kaye D, Mirembe F, Aziga F, Namulema B. Maternal mortality and associated near-misses among emergency intrapartum obstetric referrals in Mulago Hospital, Kampala, Uganda. East Afr Med J. 2003;80(3):144-9.

18. Strand RT, Campos PA, Paulsson G, de Oliveira J, Bergström S. Audit of referral of obstetric emergencies in Angola: a tool for assessing quality care. Afr J Reprod Health. 2009;13:75-85.

19. Strand RT, Tumba P, Niekowal J, Bergström S. Audit of cases with uterine rupture: a process indicator of quality of obstetric care in Angola. Afr J Reprod Health. 2010;14(2):55-62.

20. Filippi V, Ronsmans C, Gohou V, Goufodji S, Lardi M, Sahel A, et al. Maternity wards or emergency obstetric rooms? Incidence of near-miss events in African hospitals. Acta Obstet Gynecol Scand. 2005;84(1):11-6.

21. Baskett TF, Sternadel J. Maternal intensive care and near-miss mortality in obstetrics. Br J Obstet Gynecol. 1998;105(9):981-4.

22. Pattinson RC, Say L, Makin JD, Bastos MH. Critical incident audit and feedback to improve perinatal and maternal mortality and morbidity. Cochrane Database Syst Rev. 2005:4:CD002961.

23. Amata $\mathrm{AO}$. Anaesthetic and intensive care management of rupture of the gravid uterus: a review of 50 cases. Trop Doct. 1998;28(4):214-7.

24. Fawzi HW, Kamil KK, Stronge J. Rupture of the uterus in labour: a review of 14 cases in general hospital. J Obstet Gynecol. 1998;18:429-30.

25. Oladapo OT, Ariba AJ, Odusoga OL. Changing patterns of emergency obstetric care at a Nigerian University hospital. Int J Gynecol Obstet. 2007;98(3):278-84

26. Oladapo OT, Sule-Odu AO, Olatunji OA, Daniel OJ. "Near-miss" obstetric events and maternal deaths in Sagamu, Nigeria: a retrospective study. Reprod Health. 2005;2:9.

27. Prual A, Bouvier-Colle MH, de Bernis L, Breart G. Severe maternal morbidity from obstetric causes in West Africa: incidence and case fatality rates. Bull WHO. 2000;78(5):593-602.

28. Prual A, Huguet D, Garbin O, Rabe G. Severe obstetric morbidity of the third trimester, delivery and early puerperium in Niamey (Niger). Afr J Reprod Health. 1998;2(1):10-9. 
29. Kaye DK, Kakaire O, Osinde MO. Maternal morbidity and near-miss mortality among women referred for emergency obstetric care in rural Uganda. Int J Gynaecol Obstet. 2011;114:84-5.

30. Haddad SM, Cecatti JG, Souza JP, Sousa MH, Parpinelli MA, Costa ML. Applying the maternal near miss approach for the evaluation of quality of obstetric care: a worked example from a multicenter surveillance study. Biomed Res Int. 2014;2014:989815.

31. Souza JP, Cecatti JG, Haddad SM, Parpinelli MA, Costa ML, Katz L. The WHO maternal near-miss approach and the maternal severity index model (MSI): tools for assessing the management of severe maternal morbidity. PLoS One. 2012;7(8):e44129.

32. Uganda National Council for Science and Technology (UNCST). National guidelines for research involving humans as research participants; July 2014. Kampala: UNCST. p.16-22 http://www.uncst.go.ug/dmdocuments/ Human\%20Subjects\%20Protection\%20Guidelines\%20July\%202014.pdf

33. Nashef SA. What is a near miss? Lancet. 2003;361(9352):180-1.

34. Strand K, Flaatten $\mathrm{H}$. Severity scoring in the ICU: a review. Acta Anaesthesiol Scand. 2008;52(4):467-78.

35. Higgins TL. Quantifying risk and benchmarking performance in the adult intensive care unit. J Intensive Care Med. 2007;22(3):141-56.

36. Lapinsky SE, Hallett D, Collop N, Drover J, Lavercombe P, Leeman M, et al. Evaluation of standard and modified severity of illness scores in the obstetric patient. J Crit Care. 2011;26(5):535. e1-e7.

37. Lotufo FA, Parpinelli MA, Haddad SM, Surita FG, Cecatti JG. Applying the new concept of maternal near-miss in an intensive care unit. Clinics. 2012:67(3):225-30.

38. Cecatti JG, Souza JP, Parpinelli MA, Haddad SM, Camargo RS, Pacagnella RC, et al. Brazilian network for the surveillance of maternal potentially life threatening morbidity and maternal near-miss and a multidimensional evaluation of their long term consequences. Reprod Health. 2009;6:15.

39. Cecatti JG, Souza JP, Oliveira Neto AF, Parpinelli MA, Sousa MH, Say L, et al. Pre-validation of the $\mathrm{WHO}$ organ dysfunction based criteria for identification of maternal near miss. Reprod Health. 2011:8:22.

40. Kallur DS, Bada VP, Reddy P, Pandya S, Nirmalan PK. Dysfunction and organ failure as predictors of outcomes of severe maternal morbidity in an obstetric intensive care unit. J Clin Diagn Res. 2014;8(4):6-8.

41. Jayaratnam S, De Costa C, Howat P. Developing an assessment tool for maternal morbidity near miss - a prospective study in a large Australian regional hospital. ANZJOG. 2011;51(5):421.

42. Nelissen E, Mduma E, Broerse J, Ersdal H, Evjen-Olsen B, van Roosmalen J, et al. Applicability of the WHO maternal near miss criteria in a low-resource setting. PLoS One. 2013;8(4):e61248.

43. Nelissen EJ, Mduma E, Ersdal HL, Evjen-Olsen B, van Roosmalen JJ, Stekelenburg J. Maternal near miss and mortality in a rural referral hospita in northern Tanzania: a cross-sectional study. BMC Pregnancy Childbirth. 2013;13:141.

44. Moreno R, Vincent JL, Matos R, Mendonça A, Cantraine F, Thijs L, et al. The use of maximum SOFA score to quantify organ dysfunction/failure in intensive care. Results of a prospective, multicenter study. Intensive Care Med. 1999:25:686-96

45. Vincent J-L, De Mendonça A, Cantraine F, Moreno R, Takala J, Suter PM, et al. Use of the SOFA score to assess the incidence of organ dysfunction/ failure in intensive care units: results of a multicentric, prospective study. Working group on "sepsis-related problems" of the European Society of Intensive Care Medicine. Crit Care Med. 1998;26:1783-00.

\section{Submit your next manuscript to BioMed Central and we will help you at every step:}

- We accept pre-submission inquiries

- Our selector tool helps you to find the most relevant journal

- We provide round the clock customer support

- Convenient online submission

- Thorough peer review

- Inclusion in PubMed and all major indexing services

- Maximum visibility for your research

Submit your manuscript at www.biomedcentral.com/submit
Biomed Central 